\title{
A EDUCAÇÃO E A QUESTÃO DO MÉTODO: UM DEBATE SOBRE TÉKHNE E ÉLENKHOS1
}

\author{
EDUCATION AND A QUESTION OF METHOD: \\ A DEBATE ABOUT TECHNE AND ELENCHUS
}
LA EDUCACIÓN Y LA CUESTIÓN DEL MÉTODO: UN DEBATE SOBRE TÉKHNE Y ÉLENKHOS

\section{Mauricio João Farinon ${ }^{2}$}

\section{RESUMO}

Este artigo investiga um problema metodológico muito presente no contexto educacional: a tensão entre a fixação em procedimentos produtivo-instrumentais, ou a postura dialógica na qual ocorre o exame, constituição ou reconstituição dos aspectos epistémicos, existenciais e ético-morais que estão na base das ações humanas. É texto com base teórica, em perspectiva filosófica, com o objetivo de refletir sobre a presença da tékhne na educação e a necessidade de constituição do élenkhos pedagógico. Na base do argumento defendido está a concepção de que a tékhne, enquanto saber produtivo, não é suficiente para atender aos desafios ético-formativos, sendo necessária uma postura metodológica com características postas no diálogo e no exame de si. Esses critérios são próprios do élenkhos, o método dialógico socrático-platônico, o qual remete a um ambiente comunicativo, condição para a autoformação e impulso de vida. Os principais desafios na constituição do élenkhos pedagógico são pontuados pelos critérios de liberdade, alteridade, interdisciplinaridade e pensamento enquanto modo de comportamento.

PALAVRAS-CHAVE: Educação. Método. Élenkhos. Tékhne.

\section{ABSTRACT}

This article investigates a methodological problem present in the educational context: a tension between instrumental-productive procedure fixation or a dialogical attitude in which occur the examination, constitution or reconstitution of epistemic, existential and ethic-moral aspects that are the basis of the human actions. It is text with theoretical basis in philosophic perspective with the objective of reflecting on the presence of the tekhne in education and the need to constitute the pedagogical elenchus. On the bases of the defended argument is the conception that the tekhne while productive knowledge is not sufficient to meet the ethic-formative challenge, being necessary a methodological approach with dialogue and self-examination characteristics. These criteria are elenchus' own, the Socratic-Platonic dialogical method, which refers to communicative environment, condition to self-formation and impulse of life. The principal challenge in the constitution of the pedagogical elenchus are pointed by criteria of liberty, alterity, interdisciplinary and thought as mode of behavior.

KEYWORDS: Education. Method. Elenchus. Techne.

\footnotetext{
${ }^{1}$ Texto resultado de pesquisa vinculado ao EDITAL CAPES № 049/2012 - Observatório de Educação, com o título: Estratégias e ações multidisciplinares nas áreas de conhecimentos das ciências humanas, ciências da natureza e linguagens, na mesorregião do oeste catarinense - implicações na qualidade da educação básica.

2 Doutor em Educação - Pontifícia Universidade Católica do Rio Grande do Sul (PUCRS) - Porto Alegre - RS. Brasil - Professor do Programa de Pós Graduação em Educação - Universidade do Oeste de Santa Catarina (Unoesc) - Joaçaba - SC. Brasil - E-mail: mauricio.farinon@unoesc.edu.br
}

Submetido em: 15-05-2017 Aceito em: 11-09-2017

(C) ETD- Educação Temática Digital $\quad$ Campinas, SP $\quad$ v.20 $\quad$ n.1 $\quad$ p. 261-275 jan./mar.2018




\section{RESUMEN}

Este artículo investiga un problema metodológico muy presente en el contexto educativo: la tensión entre la fijación en procedimientos productivo-instrumentales o la postura dialógica en la que ocurre el examen, constitución o reconstitución de los aspectos epistémicos, existenciales y ético-morales que están en la base de las acciones humanas. Es texto con base teórica, en perspectiva filosófica, con el objetivo de reflexionar sobre la presencia de la tékhne en la educación y la necesidad de constitución del élenkhos pedagógico. En la base del argumento defendido está la concepción de que la tékhne, como saber productivo, no es suficiente para atender a los desafíos ético-formativos, requiriend o una postura metodológica con características colocadas en el diálogo y en el examen de sí. Estos criterios son propios del elenchos, el método dialógico socrático-platónico, con el que se remite a un ambiente comunicativo, condición para la autoformación y el impulso de la vida. Los principales desafíos en la constitución del elenchos pedagógico son puntuados por los criterios de libertad, alteridad, interdisciplinaridad y pensamiento como modo de comportamiento.

PALABRAS CLAVE: Educación. Método. Elenchos. Tékhne

\section{CONSIDERAÇÕES INICIAIS}

O modo como agimos e os princípios que orientam nossas ações podem parecer, ao olhar de muitos, simples reflexo de uma criação de costumes enquanto expressões subjetivas e sob os domínios do presente imediato. Abstrai-se a possibilidade de serem expressões de uma atmosfera histórica específica, cujas raízes podem ser, sim, próprias do momento presente e, nesse sentido, ainda não portadoras de raízes muito profundas no solo de uma cultura. Ou, podem ser heranças de uma história que remente a um passado mais distante e, nesse sentido, suas raízes estão profundamente postas, impondo outra dificuldade, a da percepção em toda sua extensão rizomática. Como exemplificação, a organização em nível de Estado em torno da inclusão de pessoas portadoras de impedimentos, e deficiências, derivadas, de tais impedimentos é algo recente em termos históricos, portanto, com raízes ainda superficiais no solo da cultura. A consequência prática é a dificuldade em reconhecer o outro rompendo o senso de igualdade em termos de capacidades e de aptidão em cooperar entre si, o que remete à origem e desenvolvimento das teorias contratualistas (por exemplo, Hobbes e Locke). Como outra exemplificação, expressões preconceituosas ou discriminatórias, até mesmo nacionalistas, podem conter traços de uma cultura imperial de distinção entre civilização e barbárie, remetendo aos conhecidos marcos morais muito presentes nos impérios gregos e romanos. Com isso não estou querendo legitimar modos de ação e princípios orientadores, mas, tão somente afirmar sua relação com determinado clima histórico.

As ações pedagógicas não fogem deste pressuposto: possuem relações com uma tradição (cultural, filosófica, histórica, política, antropológica, etc.) específica, muitas vezes não devidamente clara à consciência dos envolvidos. Com esse texto proponho a investigação de um problema específico que envolve a ação pedagógica, preocupado em apresentar um pequeno aspecto da atmosfera conceitual própria de um período histórico que pode ser posto como possível origem de tal problema. Falo de uma questão metodológica muito presente no contexto educacional: a tensão entre a fixação em

\begin{tabular}{|c|c|c|c|c|}
\hline (C) ETD- Educação Temática Digital & Campinas, SP & v.20 & n.1 & jan./mar.2018 \\
\hline
\end{tabular}


procedimentos produtivo-instrumentais, ou a postura dialógica na qual ocorre o exame, constituição ou reconstituição dos aspectos epistémicos, existenciais e ético-morais que estão na base das ações. É um debate, por mais que remeta à ciência moderna e os imperativos de domínio da natureza e fragmentações entre as ciências, nos leva aos conceitos de tékhne, epistéme, phrónesis e élenkhos. Embora o método do élenkhos remeta também a Homero, aos textos da tragédia, o enfoque que sigo neste texto tem como base o élenkhos socrático. Não tenho como objetivo realizar uma exegese dos diálogos de Platão a fim de situar o método elêntico no interior de tais textos - não procederei desse modo. 0 que proponho é uma apropriação do sentido formativo presente em tal método e sua relevância para os processos educativos. Na base do argumento defendido neste texto está a concepção de que a tékhne, enquanto saber produtivo, não é suficiente para atender aos desafios ético-formativos, sendo necessária uma postura metodológica com características postas no diálogo e no exame de si. Esses critérios são próprios do élenkhos, o método dialógico socrático-platônico.

É urgente o rompimento com o método próprio da ação centrada somente na finalidade produtiva, assumindo características elênticas como norteadoras das ações pedagógicas, o que pode contribuir para a educação concebida como formação. A esperança, ao retornar à tradição filosófica grega e relê-la a partir de dilemas atuais, é de autocriação, concebendo novos sentidos e motivos para o ser humano viver junto e desenvolver ações coletivas, assim como, fortificar a consciência histórica, uma vez desenvolvido o senso de relação entre o passado, o presente, os projetos e realizações futuras. Ao buscarmos recurso nos conceitos de tékhne e élenkhos, provindos principalmente do período grego clássico, estamos diante do desafio de não apenas reproduzirmos algo já posto naqueles períodos, mas percebermos possíveis atualizações de seu sentido nos nossos dias e ampliarmos a margem compreensiva e interpretativa sobre nosso momento histórico.

$\mathrm{Na}$ primeira parte apresento uma crítica ao modelo metodológico da tékhne e epistéme, destacando a necessidade de ampliarmos o debate através do conceito de phrónesis. A base teórica está mais próxima de Aristóteles em suas obras Metafísica e Ética a Nicômacos. A defesa da necessidade de um élenkhos pedagógico como alternativa ao método da tékhne e epistéme é objeto de investigação da segunda parte do texto, na qual a característica elêntica de constituição de um ambiente comunicativo é condição para a autoformação e impulso de vida. Nesse ponto, está subentendida a presença do fundamento em Platão, embora não traga os textos próprios desse filósofo. Por último, enquanto considerações finais, lanço brevemente alguns desafios à constituição do élenkhos pedagógico, pontuados pelos critérios de liberdade, alteridade, interdisciplinaridade e pensamento enquanto modo de comportamento.

\section{POR UMA CRÍTICA METODOLÓGICA}

\begin{tabular}{|c|c|c|c|c|}
\hline (C) ETD-Educação Temática Digital & Campinas, SP & v.20 & n.1 & p. 261-275 jan./mar.2018 \\
\hline
\end{tabular}


A premissa originante das reflexões deste tópico propõe a relação entre os conceitos gregos de epistéme e tékhne como um princípio metodológico fundamental para as ações pedagógicas, apontando para a relação entre a condição cognitiva do indivíduo, concebida em termos de conhecimento ou entendimento, e a aplicação sistemática dessa inteligência aos campos das atividades humanas. Com isso, remetemos à formação científica de professores com sua necessidade de intensificar os esforços para a construção de conhecimentos orientada pelo amplo leque das criações do espírito humano, às quais a universidade se constitui como congregadora ou articuladora. É importante que a formação científica atenda de modo rigoroso o desenvolvimento da condição cognitiva e a capacidade de aplicação dessa inteligência, neste caso, ao campo da educação. Mas não somente em questões de âmbito universitário, cabendo fundamentalmente aos processos formativos desenvolvidos em ambiente escolar, o esforço para a relação dada acima. A fim de sustentar minha premissa, é fundamental retomar o sentido semântico proveniente da cultura grega.

Recorro, como suporte teórico, às reflexões de Nussbaum e Wolf, em suas respectivas obras $A$ fragilidade da bondade (2009) e La filosofia y la cuestión de la vida buena (2005). Como veremos no desenvolvimento do texto, a relação da educação com a epistéme e a tékhne, por si só, não comporta ou não motiva algumas caraterísticas fundamentais para a dinâmica formativa, destacando a questão do diálogo, a capacidade de sustentação da opção teórica e ética, a ânsia pelo conhecimento e o exame de si. Para dar conta de tais características, proponho a conexão com a phrónesis aristotélica e com o método elêntico de Platão.

Inicio com um retorno à cultura grega mais antiga. A mitologia, a épica e a tragédia grega apontam para uma característica importante e que deve ser destacada: a confiança nos oráculos e nas deliberações divinas, sendo posta a tarefa do humano na descoberta de como a previsão e vontade dos deuses ganhariam corpo histórico. Ou seja, os indivíduos estavam submetidos a uma necessidade considerada fora do seu controle. Cito três exemplos ${ }^{3}$ : a) Édipo tem sua história prevista em Delfos e, a partir de então, não há fuga "tudo se cumpre claramente" (SÓFOCLES, 2015, p.191); a previsão do futuro também é característica de b) Prometeu, o qual, nas palavras de Hermes, "prevê o futuro com mais clareza e exatidão do que todos os outros deuses juntos" (STEPHANIDES, 2001, p.56). Mesmo com sua característica de divindade, Prometeu não consegue fugir da necessidade posta pela previsão e submete-se aos desígnios de seu próprio oráculo e à vontade de Zeus. Quanto à épica, cabe destacar a llíada de Homero, onde as artimanhas de Zeus levam, por exemplo, o exército grego a enfrentar a força troiana na ilusão da vitória. Cabe destacar, que é Ulisses, em sua engenhosidade, o articulador responsável por contrapor as manobras de senhor dos deuses e dos homens, levando o exército a contrariar a necessidade divina e

\footnotetext{
${ }^{3}$ Os três exemplos citados são postos de modo rápido e centrado em apenas um aspecto: indicar, em linhas gerais, a característica de uma necessidade tida como estando fora do controle humano.
} 
atingir a vitória.

A fé nos deuses olímpicos e a consequente crença nos oráculos nos põem diante de uma religiosidade e de uma cosmovisão caracterizados por dois modos de ações, os quais se desenvolvem simultaneamente: "uma no mundo superior dos deuses, a outra na terra, e tudo o que sucede aqui embaixo acontece por determinação dos deuses. A ação humana não tem nenhum início efetivo e independente; o que é estabelecido e realizado é decisão e obra dos deuses" (SNELL, 2005, p.29).

Se entendermos a tékhne como arte, é possível encontrar no próprio Prometeu uma explicação para sua origem, sendo posta, aqui, como parte daquilo que Bruno Snell (2005) chama de etapas do caminho percorrido pelos gregos até chegar à descoberta do espírito. Mas a tékhne dada por Prometeu aos seres humanos ainda não está envolta com a característica de relação com a epistéme que assume com Platão e Aristóteles - normal, pois é uma primeira etapa do caminho para a descoberta do espírito. No mito de Prometeu, a arte ou o engenho não minimiza os efeitos da necessidade oracular ou dos desígnios dos deuses, se constituindo apenas em um modo de produzir objetos que ajudassem as pessoas em suas tarefas, como que em um alívio para os infortúnios e dificuldades.

Cabe um destaque: com a arte ensinada por Prometeu, passou a existir somente "uma diferença entre os deuses e os homens: estes eram mortais, ao passo que aqueles viviam eternamente. [...] Tais progressos desagradaram a Zeus, pois [...] sabendo usar o fogo, tornaram-se ainda mais fortes. O senhor dos deuses e dos homens começou a temêlos" (STEPHANIDES, 2001, p.19). O que temos é um vislumbre daquilo que a tékhne significará com a filosofia grega, ou seja, a ideia de que, pela arte, podemos romper com os nexos causais postos pela concepção religiosa e cosmológica, instaurando o modo especificamente humano de vida. Prometeu não consegue fugir da necessidade causal posta pelo oráculo ou pela vontade de Zeus, mas os seres humanos, em posse da arte, tornam-se ameaça à hegemonia causal dos olimpianos.

A impressão é de uma dependência a algo que foge do controle dado por um plano estritamente posto pelo ser humano. É diante dessa percepção que o grego começa a se preocupar ou questionar a contingência sem controle dada pela necessidade divina e oracular, sendo nesse ponto que a força residente na fortuna começa a ser superada pela força cuja origem está na arte. Nussbaum destaca:

Se a vida humana parecia mais do que nunca exposta à týkhe em todas as suas formas, os atenienses estavam também mais do que nunca dominados pela ideia de que o progresso poderia trazer a eliminação da contingência sem controle da vida social. Essa esperança encontra expressão numa antítese e numa história: o contraste entre týkhe, fortuna, e tékhne, arte ou ciência humana (2009, p.79). 
$\mathrm{Na}$ perspectiva filosófica clássica, a tékhne concebe-se a partir do critério de universalidade a qual, não restringido aos aspectos particulares, visa o controle mediante o conhecimento abrangente, estando em íntima relação, na perspectiva platônica, com a epistéme. Nussbaum destaca muito esse aspecto em sua obra A fragilidade da bondade (2009, p. 390), seja significando tais conceitos, seja em suas reflexões derivadas. Vale destacar, a partir da obra: - epistéme concebida como corpo de conhecimento, entendimento, saber, conhecimento; designa a condição cognitiva do agente; - tékhne, por sua vez, é concebida como artifício, arte, ciência, enquanto aplicação sistemática da inteligência a qualquer campo da atividade humana.

Aplicado ao contexto da paidéia em Platão, temos a intimidade entre ambas as ações, pois a condição cognitiva do agente deve remeter à capacidade de produção, de aplicação sistemática dessa inteligência. Foge, ao menos nessa interpretação, a possibilidade de o artifício, a arte, ocorrer desconectada do conhecimento ou corpo de conhecimento. Por outro lado, a epistéme tem como objeto a tékhne, se aplica a ela. Com base em tal concepção, pontuo uma crítica profunda às posturas pedagógicas nas quais se esvaziam os conceitos e as relações entre tékhne e epistéme. Quando se abstrai de tais posturas, a caraterística de arte passa a não significar uma aplicação sistemática da inteligência, ou seja, as ações pedagógicas não partem de um corpo de conhecimento elaborado, não refletem uma condição cognitiva esclarecida (para utilizar uma expressão moderna), estando mais relacionada à aplicação de receituários didáticos desprovidos de entendimento, o que se relaciona com o espontaneísmo e ação irrefletida. A aplicação da inteligência gera uma disposição segundo a qual a "pessoa que vive pela tékhne trata cada nova experiência com presciência ou engenho. Possui uma espécie de apreensão sistemática, alguma maneira de ordenar a matéria, que a levará à nova situação bem preparada, livre da dependência cega do que acontece" (NUSSBAUM, 2009, p. 84).

Quando nos deparamos com a necessidade e os desafios de uma apreensão sistemática e do preparo que nos livra da dependência cega, estamos diante de um esforço em duas direções: a) estabelecimento de características comuns entre os fatos (universalização ${ }^{4}$ ) e distinção das características específicas (particularização); b) constituição de referenciais de ação a partir de experiências anteriores, o que deve ser acompanhado pela capacidade reflexiva/criativa em tratar cada novo caso enquanto

\footnotetext{
${ }^{4}$ Considero importante destacar que o atual debate Filosófico-Educacional questiona a legitimidade da universalização, inserindo a concepção de mundo comum, o qual se constitui pela inserção do ser humano no âmbito das experiências intersubjetivas, e não sob princípios metafísicos e postos como um a priori ao qual o ser humano deve ser acoplado. Ver, por exemplo: HERMANN, Nadja. Autocriação e horizonte comum ensaios sobre educação ético-estética. ljuí: Ed. Unijuí, 2010. - (coleção Fronteiras da educação); também, TIBURI, Marcia; HERMANN, Nadja. Diálogo/Educação. São Paulo: Editora Senac São Paulo, 2014.
} 
indivíduo experiente, mas, principalmente, aptos a avaliar a situação particular e estabelecer modos de ação coerentes com as exigências postos pela contingência - em outras palavras, estabelecendo o que se pode chamar de dialética entre individuação e universalização, experiência e novidade.

Nesse sentido, a perspectiva de Platão e de Aristóteles encontram uma relação de proximidade, ou seja, a necessidade de estabelecer relativa segurança nas ações constitui o âmbito da relação entre epistéme e tékhne. A partir da Metafísica de Aristóteles (I, 981a), a tékhne se origina "quando de muitas observações experimentais surge uma noção universal sobre os casos semelhantes", correspondendo, conforme o filósofo, a um saber proveitoso em relação a todos os indivíduos de uma determinada constituição ou características. Seguindo, ainda, o mesmo fragmento da Metafísica, isso difere da experiência enquanto "conhecimento das coisas singulares". A noção universal presente na tékhne e em Aristóteles, não faz parte do debate sobre a ética, pois conforme Cenci (2012), o ato próprio da tékhne é a produção de objetos, o que é pautado pelo seguimento de passos previamente estabelecidos. A Metafísica (I, 981b) faz essa referência ao indicar, como já citado, o ponto de partida da tékhne posto na constituição ou noção universal, portanto, um trabalho ou atividade que tem como base conhecimentos sólidos, rompendo ou com o impulso natural ou com a ação por costume, os quais são próprios, respectivamente, dos seres inanimados e dos operários. Esta solidez na base de conhecimentos se forma pela dinâmica inter-retroativa entre, por um lado, o corpo de conhecimento e a condição cognitiva do agente e, por outro, a aplicação desse conhecimento aos mais diversos campos da ação humana. Coloco a centralidade na denúncia aristotélica ao problema da ação por costume, em um movimento irrefletido e não perceptivo, ou não consciente sobre as mudanças antropológicas, éticas e históricas que acompanham todo indivíduo ou grupo humano. Desse modo, tem-se um duplo sentido de não renovação ou ingenuidade: a) no corpo de conhecimentos e na própria condição cognitiva, o que leva à execução de ações orientadas por princípios obsoletos; b) no procedimento que visa a realização de determinada meta, ocasionando a inflexão em direção ao mecanicismo ou, em termos educacionais, ao didatismo que acompanha os processos de ensino e aprendizagem.

Os elementos até então colocados fazem referência à qualificação em termos de epistéme e tékhne, o que significa a qualificação no conhecimento ou na produção decorrente. Mas, cabe aqui o elemento adversativo, não visa aperfeiçoar os sujeitos envolvidos ou que agem, mas tão somente o produto resultante do trabalho:

o trabalho como poiesis não se vincula com a práxis, isto é, com a ação e a virtude moral. Os trabalhadores não precisam ter a necessidade de muitas virtudes, e os escravos, de nenhuma, pois o tipo de vida que levam não permite aprimorarem as qualidades morais. Desse modo, não há relação entre virtude e trabalho, eles são coisas distintas e por vezes parecem ser excludentes (CENCl, 2012, p.75). 
Se a atividade educacional-formativa for colocada no âmbito da tékhne, cabe a pergunta por qual é - ou qual deveria ser - o produto resultante desse trabalho. Por outro lado, se tal atividade for colocada no âmbito da práxis, e não sendo relacionada com um produto, qual é seu fim? Vinculada à política e a vida na polis, a formação não pode abstrair do fim que deve ser almejado pela ciência política: o bem do homem (EN $\left.{ }^{5}, 1,1094 a\right)$, o qual não é conhecimento, mas ação (EN, I, 1095a) e, enquanto ação, somente pode ser desenvolvida por indivíduos singulares, mesmo que concebidos como membros de um comum. É possível pontuar a referência a consideração individual que deve estar presente nas ações humanas. Na efetivação do agir bem, posta aqui como finalidade da atividade educacional-formativa, experiência e arte podem ser postos como dois elementos intercruzados pois, por um lado, o bem do homem é a finalidade da ciência política, sendo mais completa a finalidade da cidade do que a de um homem isolado (EN, I, 1094a-b). Por outro lado, a experiência ou consideração individual é fundamental, pois, conforme Metafísica (I, 981a) não é o homem que o médico cura, mas a Calias ou a Sócrates, que além disso, é homem. Em termos educacionais, isso nos lança a um desafio de proporção hercúlea, uma vez sendo a educação a responsável pelas condições que tornam os indivíduos aptos a agirem bem, o que demanda constante atenção à relação entre o indivíduo que age e o princípio político que orienta, ou entre a noção geral e a sua aplicação/reconsideração frente aos casos particulares.

O termo aristotélico utilizado para definir esta habilidade moral e, portanto, não produtiva, de transitar entre a noção geral e a sua aplicação/reconsideração frente aos casos particulares, denomina-se phronesis. A phronesis, ou a excelência da sabedoria prática que nos leva a deliberar bem, "consiste na aplicação de um princípio geral a cada caso particular, que depende de um acurado processo de observação, denominado por Aristóteles de aisthesis" (HERMaNN, 2010, p.68). Tangenciando a questão da aisthesis, centro a atenção na relação entre indivíduo e sociedade pautado pelo sentido de phronesis como capacidade de "enfrentar a oposição entre o caráter universal dos princípios morais abstratos e a particularidade dos contextos históricos e da autocriação do eu" (p.77). 0 espaço formativo exigido para esse movimento põe as ações pedagógicas na dificuldade, também, no princípio ético de preparar os indivíduos não apenas para seguirem as determinações contextuais, mas serem capazes de escolha e, principalmente, criadores de alternativas diferenciadas daquelas já estabelecidas pelo contexto, o que é próprio da novidade que eles representam. Por isso é que a educação é posta no âmbito da práxis e responsável por formar essa capacidade de "deliberação prudente, enquanto compreensão prática que pode auxiliar no enfrentamento da tensão [...] entre a criação do eu singular e a integração na comunidade (ethos comum)" (p.77). Em complemento a essa ideia, a autora ainda destaca:

\footnotetext{
${ }^{5}$ Abreviação da obra Ética a Nicômacos, de Aristóteles.
} 
Considerando que a educação produz a individualidade e a socialização, pretendese demonstrar que a phronesis atende às contingências dos contextos e as singularidades do eu como algo que não é irreconciliável com as normas universais. Assim pode ser dissolvida a oposição [grifo meu] entre formar o eu (individualização) e integrá-lo numa comunidade (socialização), criando espaço para o discernimento compreensivo da situação do outro (HERMANN, 2010, p.78).

No lugar de uma oposição, proponho pensarmos em termos de uma dialética, não na ilusão hegeliana de gerar uma síntese, mas na provocação adorniana de uma consciência sobre a não-identidade e sobre a importância do enriquecimento da experiência, própria do permanecer em relação com o diferente, com o contraditório, com a alteridade. Em 981a da Metafísica, tem-se a compreensão aristotélica de que a arte pode ser ensinada, e isso devese ao caráter de universalidade que a compõe, a qual garante segurança no princípio de ação. Em relação à experiência, cuja centralidade está posta na consideração individual, essa não pode ser ensinada, pois o caso particular pode estar em não conformação com as determinações gerais. Isso leva a uma forte consequência em termos éticos, pois demanda uma sabedoria prática que nos torna apto à novidade nos critérios e dinâmicas de ação. Não ocorrendo princípios orientadores universais, que são abstratos, a experiência exige a constante renovação e qualificação no próprio indivíduo que age. Pela tékhne temos a vantagem de vivenciar cada nova situação como indivíduos experientes e guiados pela orientação geral construída. Por outro lado, a tékhne nos põe diante da insuficiência da orientação geral frente às novidades ou especificidades de cada situação. Mesmo tendo sido tangenciada na Metafísica, ponho a experiência como elemento ético que, vinculado à phronesis, permite constantemente problematizar e reelaborar a orientação geral, em um constante movimento de autoformação. Hermann (2010, p.80-81), localiza a phronesis em seu envolvimento com a particularização, o que pode ser aproximado com o conceito de experiência concebido na perspectiva aristotélica:

A phronesis é uma sabedoria prática porque diz respeito à ação que envolve os casos particulares, por isso as ações humanas não podem ser pensadas com os conceitos da ciência teórica. Uma techné se ensina; entretanto, a phronesis não é ensinável, pois não se pode, a priori, determinar quais os meios morais mais adequados para determinados fins. Ou seja, não é possível alguém possuir um conhecimento antecipado, que lhe assegure como agir em cada situação, devido às singularidades e exigências imanentes à própria situação, mas apenas um conhecimento mais profundo das características da vida.

O âmbito do desenvolvimento moral, próprio da ética, chama por alguns pressupostos distintos: em Platão encontramos o recurso ao élenkhos e, em Aristóteles, o recurso a uma prática política orientada pela phronesis. O ponto comum está na necessidade de uma coletividade, enquanto um conjunto de indivíduos que se colocam em relação dialógica, mimética e racional. O que cabe, ao menos neste momento, é um esclarecimento maior sobre o recurso ao élenkhos. Portanto, nas linhas que seguem, mantenho referência a esse elemento metodológico. 


\section{EM DEFESA DO ÉLENKHOS PEDAGÓGICO}

Márcia Tiburi adverte, em diálogo com Nadja Hermann, sobre a necessidade de a educação ser concebida como ética. Não fala de uma educação ética ou educação para a ética, mas "educação como ética", como atividade ou processo "que não apenas ensina o respeito pelo outro, mas ela mesma é processo de respeito ao outro". E sinaliza com preocupação: "não penso que a educação hoje promova esse respeito" (TIBURI; HERMANN, 2014 , p. 24 - grifo meu). No próprio argumento de Tiburi pode ser encontrada alguma luz para compreender o problema dessa ausência de identidade entre educação e ética. Refirome a concepção de educação como atividade de ensino, onde alguém tem tal tarefa frente a outros que precisam aprender, gerando uma distância linguística própria do lócus de um professor ensinante e de um aluno aprendente. O que se perde nisso é a própria educação e, nas palavras da professora Márcia Tiburi, a própria ética, uma vez sendo concebidas de modo indissociáveis.

Frente as tendências tecnicistas, a educação em sua concepção de ensino e aprendizagem pode até ser válida, uma vez que se faz necessário somente a apropriação de modos de procedimento previamente postos como corretos e condutores supostamente infalíveis ao resultado esperado. Essa postura não é rara na educação, povoando o imaginário de professores dedicados ao letramento, a instrumentalização dos processos e padronização dos resultados (sejam resultados em termos morais, sejam resultados em termos de conteúdo). Na concepção de educação como ética ocorre um espaço de criação, próprio de um espaço de liberdade, onde os envolvidos no processo fazem a experiência da autoformação gerada pela relação dialógica que permite o exame de si. Todos os envolvidos em tal experiência são sujeitos deste ato dialógico, de exame e constituição de si. Tais aspectos são características próprias dos diálogos de Platão, sendo esse processo denominado élenkhos, um modo de ação que permite a elevação epistêmica, existencial e moral. Acima, e sob o critério da phrónesis, propus a ampliação de método pautado pela relação entre epistéme e tékhne; neste momento do texto apresento outra característica metodológica a ser considerada pelos processos educativos, denominado aqui de método elentico.

Em primeiro lugar é importante destacar um elemento da literatura ${ }^{6}$ sobre o tema do élenkhos: na abordagem socrática presente nos diálogos de Platão, ele é concebido como a descrição daquilo realizado pelos envolvidos na ação dialógica, ou seja, um procedimento que visa, por meio da investigação, encontrar a verdade sobre questões morais. Enquanto

\footnotetext{
${ }^{6}$ Ver, principalmente, Gergory Vlastos, em seu texto The Socratic elenchus. Também, Estebam Bierda, Elenchos, intelectualismo y vergüenza en el Gorgias de Platón (2014); Janaína Silveira Mafra, As principais mutações semânticas do Élenkhos do século VIII a.C. ao início do século IV a.C. (2009); Fernando Muniz, Performance e Élenkhos no Íon de Platão (2012).
} 
exame crítico a que se é submetido via élenkhos, ocorre duplo e interconectado objetivo: "descobrir como todo ser humano deve viver e examinar o ser humano singular [...] para descobrir se ele está vivendo como deve viver" (VLASTOS, THE SOCRATIC ELENCHUS, p. 44 tradução minha). É importante destacar a crença problemática na existência e busca por um modo ideal de vida, algo aceitável universalmente, sendo que o modo como o indivíduo vive deve estar coerente com o modo como o ser humano deve viver.

O elemento que proponho como determinante na questão socrática sobre como devemos viver é a importância do espaço de criação promovido pelo diálogo, enquanto crítica aos referenciais previamente existentes. Mediante o diálogo promovido interrogativamente, o élenkhos possui o potencial de gerar um movimento de construção de novos referenciais enquanto algo próprio de um projeto de elevação cultural. Em termos amplos, este espaço de criação elêntico não se caracteriza pela imposição de ideias universais sobre os casos singulares, mas pela reflexão possibilitadora da tomada de consciência sobre as fragilidades e potencialidades das concepções, compreensões, ações e modos de vida dos indivíduos, ao mesmo tempo em que visa à qualificação em tais aspectos. Desse modo, não visa a fixação de princípios universais e de totalizações, os quais desconsideram as pluralidades de orientações em favor da unificação que surge a partir de um ideal de humanidade. O élenkhos, conforme Vlastos (THE SOCRATIC ELENCHUS, p. 37), não é a tentativa de conduzir a uma verdade, com a garantia de respostas seguras ou na certeza de estarmos sendo postos diante de princípios de vida universalmente válidos. Para o autor, o élenkhos não é usado como nomeador, mas como descritor sobre aquilo que Sócrates faz - o que e como ele faz para buscar respostas ou permitir ao interlocutor construir as respostas por ele mesmo através do exame sobre o mundo, sobre si e sobre suas concepções. Nesse sentido, o élenkhos em sua característica própria de diálogo, constitui um ambiente comunicativo de encontro sensível com o outro (diverso em termos de concepções, orientações, modos de pensar, agir, habitar o mundo), não como tentativa de uniformização, de posse ou controle, mas enquanto originador do trauma que nos faz pensar reflexivamente, enquanto impulso de admiração que origina o ato filosófico e, por que não, que origina o ato autoformativo.

Um aspecto positivo surge da afirmação de Vlastos, acima destacada: estamos diante da preocupação sobre a) o modo como devemos viver e, b) os critérios a serem seguidos para resolvermos os problemas que envolvem nossa vida em sociedade. Seguindo essa concepção, a tarefa do élenkhos está envolta em preocupações morais e visa dar respostas aos dilemas que assolam o viver humano. Portanto, não envolve, necessariamente, o procedimento produtivo ou, em termos modernos, o procedimento técnico. Por exemplo, não se trata de definir o melhor modo de manusear a espada ou se mover pelo campo de batalha, mas, sim, de um debate sobre como deve ser conduzida a educação do guardião e, em última instância, como deve ocorrer a educação do ser humano que vai formar a cidade; outro exemplo, não se trata de saber calcular a área de uma figura geométrica, para a qual

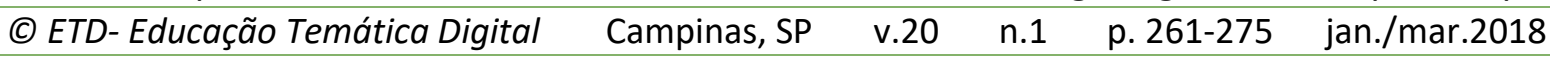


basta o domínio técnico, mas de saber como a geometria pode nos aproximar da ideia do bem ou, ainda, como o cálculo facilita nossa alma a passar da mutabilidade para a verdade e essência ${ }^{7}$.

Parece que, em relação a esse aspecto, vivemos um desvio de foco em nossas ações pedagógicas, cujas preocupações são reduzidas àquilo que a tékhne proporciona, ou seja: ao domínio do cálculo para transações comerciais; o domínio gramatical para o uso erudito da língua e o trânsito internacional; a clareza histórica para sermos - em temos utilizados por Eric Hobsbawm - bons cronistas, compiladores ou memorialistas; negligenciando a tarefa de gerar espaços de autocriação e de impulsos de vida. Sem abstrair da relativa importância instrumental das matérias escolares, conforme apontei acima, as ações pedagógicas e seus processos educativos parecem estar se limitando a gerar domínio de um procedimento eficaz que garanta o resultado mensurável em termos de média aritmética ou de satisfação das exigências da sociedade capitalista-industrial. Seguindo os traços da phrónesis, o élenkhos está preocupado com uma qualidade diferenciada, a elevação moral que ocorre no momento em que, inseridos nas experiências da vida e no diálogo constitutivo das relações, nos constituímos em humanidade. O que ocorre é a inexistência de um elemento articulador entre o impulso instrumental e o impulso de vida, um elemento articulador entre as exigências produtivas derivadas do domínio dos conteúdos e a exigência de qualidade na condição humana. A ausência dessa articulação se visualiza pela constatação empírica de um oposto ao impulso de vida: tendências destrutivas de si e de outrem, ocasionada por indivíduos fortes em conhecimentos disciplinares, mas frágeis em subjetividade e intersubjetividade, abandonados em sua alma, naquilo que os tornam humanos, convertidos em máquinas utilitárias cujos resultados de seus esforços não possuem outra qualificação além do monetário.

Passa a ser compreensível a observação de Ursula Wolf quando afirma a impossibilidade de adequar a tékhne às necessidades éticas postas pela busca do bem viver $^{8}$. Afirma (2005, p. 53) que o saber da tékhne não é suficiente, sendo necessário outro tipo de saber que não segue tal método. Para a autora (p. 54), em Platão somos postos diante de um outro método, e este novo modo de proceder é o modo originado pelo élenkhos, sendo uma de suas características principais, e seguindo ainda a mesma obra, o fato de não "examinar as opiniões de modo isolado, mas, pelo contrário, estas são investigadas enquanto sistema de convicções que uma pessoa possui" (p. 55 - tradução minha) e postas em exame cruzado a partir da efetivação de um ambiente socialmente dialógico. A defesa é que esse exame próprio do método ou do procedimento elêntico permite a elevação moral que ocorre somente pelo fato de o exame ocorrer sob a

\footnotetext{
${ }^{7}$ Os exemplos aqui postos têm como base a obra $A$ República, de Platão.

${ }^{8}$ Já desenvolvi o argumento sobre isso na primeira parte deste texto, ao abordar os aspectos da universalidade e do vínculo da tékhne somente com a epistéme.
} 
luminosidade da relação com outrem. Por isso, a proposta de tornar a sala de aula, ou qualquer outro ato de encontro, um ato elêntico, assume uma extrema relevância uma vez concebendo a sala de aula como espaço não de letramento ou instrumentalização, mas de constituição do humano, de potencialização de impulsos de vida, para os quais os conteúdos podem ser fundamentais desde que sigamos os critérios postos em $A$ República, enquanto meios de formação de um modo adequado de viver em sociedade, de colocação e busca pelo bem o qual, e agora me afastando de Platão, não é conhecimento de uma ideia, de uma essência, mas como a busca de alternativas para evitar que injustiças ocorram no mundo da vida.

\section{DESAFIOS NA CONSTITUIÇÃO DO ÉLENKHOS PEDAGÓGICO: ALGUMAS CONSIDERAÇÕES FINAIS}

A experiência humana no mundo é angústia, pois nos lança no trauma da existência onde nada é passividade, mas constante decisão. Portanto, a existência desestabiliza ou elimina o conforto do eu colocado em-si e para-si, pois, decidir, é ato próprio, mas não no isolamento do eu que se considera imune a angústia, principalmente do desconhecido. Se a existência é angústia, a decisão nos lança para o alto, permitindo aquilo que Heidegger (2008) define como um cair para o alto, quando, na experiência que parece abismal, percebemo-nos em constituição. A ação elêntica parece se originar enquanto experiência de angústia e, também, provocar tal experiência, uma vez que não nos dispomos ao élenkhos se estivermos enrijecidos pelos dogmas ou verdades absolutas, ao mesmo tempo em que ele se constitui como potência de abismo, dada a característica de exame que, em ato dialógico, abala as referências de mundo e gera as condições de reconstruí-las em um movimento de elevação moral. Eis o que é a liberdade: este liberar-se do medo da angústia e lançar-se na incerteza de mundo - terreno fértil para a fecundidade do humano. $O$ que valida esse humano? Sua radical queda para o alto, a qual, enquanto consciência de finitude, não nos faz buscar a plenitude, mas a infinitude, enquanto permanente esforço de autocriação.

Nesses termos, o élenkhos é compreendido como método para os processos formativos, por ser um caminho de pensamento (outra expressão heideggeriana) diante da existência humana que, no mundo, se sente desafiada à decisão. Constituir o élenkhos é lançar as condições para a experiência com outrem, um ambiente comunicativo de encontro sensível, no qual é possível o aperfeiçoamento epistemológico e, principalmente, moral. Acredito que isso deve ser a educação e isso deve constituir o espaço denominado sala de aula.

Outro desafio que surge das reflexões postas neste texto, refere-se à alteridade. Essa tematização é posta como própria do procedimento elêntico pelo olhar de um habitante do século XXI. Tenho dúvidas sobre o reconhecimento da alteridade na filosofia grega. Mas

(C) ETD- Educação Temática Digital Campinas, SP $\quad$ v.20 $\quad$ n.1 $\quad$ p. 261-275 jan./mar.2018


defendo que, nela, se abre a possibilidade para a tematização e concepção de alteridade. E, nisso, o élenkhos ganha forma ética, fundamentando os processos formativos, pois a presença do outro no encontro elêntico ocorre como um vir sem possibilidade de controle: o outro vem não para atender as minhas pretensões, ele desinstala as certezas, a ânsia por controle ou a vontade de poder enquanto domínio. O aparecer do outro constitui-se, portanto, em realidade, impassível de negligenciar, sendo que esse próprio aparecer constitui radicalmente o élenkhos, por ser impulso comunicativo. Do contrário, não é aparecer, mas um responder à minha invocação.

É no âmbito do pensar que o élenkhos apresenta seu maior desafio. Coloco-me nos caminhos de Levinas: pensar não é contemplação, mas é engajamento, no sentido de um envolver-se com o acontecimento dramático que é a existência humana no mundo. É, portanto, modo de comportamento pelo qual nos pomos em relação com a alteridade do mundo, com a alteridade do humano, as quais desinstalam as certezas e nos obrigam a depararmo-nos com o estranho, com o diferente e a revisitar e reconstruir os fundamentos de nossas decisões e ações.

Por último, o élenkhos abre um vasto caminho para a interdisciplinaridade e para a transdisciplinaridade, uma vez que sua característica básica é a ação e busca conjunta de solução aos problemas, sejam em termos procedimentais, ou em termos morais e que envolvem os modos de conduta, ou em termos epistemológicos e que envolvem o problema relativos ao entendimento humano. Agir elenticamente é estar disposto a colocar-se como um aprendente em um horizonte de possiblidades que surgem na relação com os diferentes modos de ser e de pensar, na relação com diferentes conteúdos e diferentes disciplinas. Através da ação elêntica percebemos a importância da comunidade linguística a partir da qual se ampliam as possibilidades de qualificação dos processos educacionais, para além do indivíduo isolado e autossuficiente.

Destaco que não estou em defesa da anulação da tékhne, mas em defesa de sua insuficiência quando a preocupação está na educação enquanto formação. Por isso, o que proponho é um método educacional guiado pela phrónesis e pelo élenkhos.

\section{REFERÊNCIAS}

ADORNO, Theodor; HORKHEIMER, Max. Dialética do Esclarecimento: fragmentos filosóficos. Tradução de Guido Antonio de Almeida. Rio de Janeiro: Jorge Zahar, 1985.

HEIDEGGER, Martin. A caminho da linguagem. Tradução de Marcia Sá Cavalcanti Schuback. 4.ed. Petrópolis: Vozes, 2008.

NUSSBAUM, Martha. A fragilidade da bondade: fortuna e ética na tragédia e na filosofia grega. Tradução de Ana Aguiar Cotrim. São Paulo: Editora WMF Martins Fontes, 2009. 
TIBURI, Marcia; HERMANN, Nadja. Diálogo/Educação. São Paulo: Senac, 2014.

SNELL, Bruno. A cultura grega e as origens do pensamento europeu. 1a reimpressão. Tradução de Pérola de Carvalho. São Paulo: Perspectiva, 2005

SÓFOCLES. Rei Édipo. Tradução de Flávio Ribeiro de Oliveira. São Paulo: Odysseus, 2015.

Prometeu, os Homens e outros mitos. Tradução de Marylene Pinto Michael. São Paulo: Odysseus, 2001.

VLASTOS, Gregory. The socratic elenchus. Disponível em: Disponível em: http://socrates.arts.ubc.ca/blog/wp-content/uploads/2015/09/Vlastos-Elenchus.pdf Acesso em: 08 mai. 2017.

\footnotetext{
${ }^{\mathrm{i}}$ Revisão grammatical do texto sob a responsabilidade de:
}

Ana Paula Pauletti Jobim

- Graduada em Letras - Português e Espanhol e Respectivas Literaturas (URI)

- Pós-graduada em Metodologia de Língua Portuguesa e Literatura (URI)

- Mestre em Linguística (UPF) 